\title{
Analysing Four Prosodic Forms to Convey the Pragmatic Function of Dominance and Control in L2 Monologic Discourse
}

\author{
Raúl Jiménez Vilches \\ Universidad Autónoma de Madrid, Universidad Complutense de Madrid ${ }^{1}$ \\ raul.jimenez@uam.es,rjimen04@ucm.es
}

\begin{abstract}
This paper reports the findings from a study of the learning of English intonation by Spanish speakers within the discourse mode of L2 oral presentation. The purpose of this experiment is, firstly, to compare four prosodic parameters before and after an L2 discourse intonation training programme and, secondly, to confirm whether subjects, after the aforementioned L2 discourse intonation training, are able to match the form of these four prosodic parameters to the discourse-pragmatic function of dominance and control. The study designed the instructions and tasks to create the oral and written corpora and Brazil's (1994) Pronunciation for Advanced Learners of English was adapted for the pedagogical aims of the present study. The learners' pre- and post-tasks were acoustically analysed and a pre / post- questionnaire design was applied to interpret the acoustic analysis. Results indicate most of the subjects acquired a wider choice of the four prosodic parameters partly due to the prosodically-annotated transcripts that were developed throughout the L2 discourse intonation course. Conversely, qualitative and quantitative data reveal most subjects failed to match the forms to their appropriate pragmatic functions to express dominance and control in an L2 oral presentation.
\end{abstract}

Keywords: prosody, intonation, L2 discourse intonation, L2 pragmatic competence, L2 non-specialist public speaking

\footnotetext{
${ }^{1}$ Part-time lecturer
} 


\section{Introduction}

\subsection{Prosodic Development in L1 and L2}

The process by which prosody develops in a language is unique (Bolinger 1986; Cruz-Ferreira 1987; Ladd 1996; Hirst and Di Cristo 1998; Ramírez Verdugo 2003, 2006). In fact, L1 learners start acquiring some prosodic and intonational traits from the very beginning of their linguistic developments (Crystal 1986; Lieberman 1986; Mehler, Jusczyk, Lambertz, Halsted, Bertoncini, and Amiel-Tison 1988; Snow and Balog 2002). They are capable of imitating the sounds and also of matching a wide range of pitch patterns to their respective discourse-pragmatic functions depending on the contexts that take place within the communication of basic needs to their parents (Halliday 1975; Cruttenden 1997; Prieto Vives, Borràs-Comes, Crespo-Sendra, Thorson and Vanrell 2011). During the process of obtaining an L1 proficiency, prosody and intonation stay in the background and become subconscious and automatic (Berkovits 1980, Cutler 1984, Snow 1995, Ramírez Verdugo 2005, Ramírez Verdugo and RomeroTrillo 2005). When it comes to Second Language Acquisition, the learner's interlanguage phonology results from the complex interplay between the mother tongue (L1), the target language (L2), and internal developmental processes (Pavón Vázquez 2001). More specifically, non-native speakers do not normally develop their L2 prosody and intonation as they do in their L1. The specific prosodic forms and functions of the new language are not internalised as in the L1 and accordingly the L2 speakers remain unaware of the L2 prosodic intricacies. What they seem to do instead is to transfer and overgeneralise L1 phonological processes at segmental level (Monroy Casas 2001) and suprasegmentally the intonation patterns of the L1 to the L2 (Ramírez Verdugo 2006). "Therefore, learners would need to be aware of specific prosodic features in the L2, different from those of their $\mathrm{L} 1$, in order to be able to organise their speech appropriately and convey the intended pragmatic meaning and information (Ramírez Verdugo 2006: 142)". However, intonation is hardly taught in the English EFL classroom at compulsory level in countries such as Spain. And when intonation is actually taught, it is done at sentence level but not at discourse level - although a shift towards a discourse approach in the teaching of L2 pronunciation is progressively becoming more widespread (Pavón Vázquez 2001). Interestingly, mastering discourse intonation is crucial for the L2 learners to become communicatively competent not only in their interactions with other speakers but also in monologic speaking style.

\subsection{Discourse Intonation Approach}

An appropriate study of the form, meaning and function of intonation must go beyond the sentence level and must include larger stretches of speech, which are the scope of an area of linguistics called discourse intonation. This approach started in the British Isles and was developed by David Brazil (1975, 1978, 1985, 1997) and others (Brazil, Coulthard and Jones 1980; Coulthard and Brazil 1981; Coulthard and Montgomery 1981; Sinclair and Brazil 1982; Hewings 1990; Cauldwell 2003) who worked on combining discourse analysis and intonation (Yule 1980, Sinclair and Brazil 1982, Brown and Yule 1987). Discourse intonation advocated the study of intonation from the point of view of the user, its function in context and its communicative value. Discourse intonation approached English intonation as a well-defined set of prosodic features that the speaker can choose and those choices do not have grammatical and attitudinal meanings. Therefore discourse intonation did not follow O'Connor and Arnold (1961) who described tones as a result of the speaker's attitude. With regard to the grammatical function of intonation, Brazil (1975) adopted Halliday's (1963) five tones and his meaning-based phonological typology, although Brazil did not include any of the Halliday's grammatical forms. Discourse intonation was also in opposition to the American school (Chomsky and Halle 1968, Liberman 1977, Pierrehumbert 1980) that formulated rules in generative approaches. On the other hand, later work on generative phonology (Pierrehumbert and Hirschberg 1990) adopted a 
more functional, discourse-based approach and their focus was on the role of intonation in natural communication and interaction.

Following Brazil's approach, in specialised discourse types there are participant specific roles that determine the prosodic choice available to speakers within the discourse intonation system. These participant specific tones are the rise tone and the fall-rise tone. The decision to choose one of these two is made in terms of fall-rise/fall or fall/rise-fall and, in Brazil's terms, the rationale behind these choices is the role relationships between the participants in a discourse. When a speaker is dominant, he/she has greater responsibility for the discourse and greater freedom in making linguistic choices, including the fall-rise/rise choice. This concept would apply to contexts such as the teacher in classroom talk, the interviewer in an interview, a person giving a speech in front of an audience, and so on. Other authors like DuBois, Schuetze-Coburn, Cumming and Paolino (1992) went beyond a mere description of discourse and highlighted the importance of a discourse interpretation and the need for research tools. Although they used the traditional British five tones, they added five main prosodic parameters that contribute to determine the boundaries of intonation units: "(1) coherent contour: a unified intonation contour, i.e. one displaying overall gestalt unity; (2) reset: a resetting of the baseline pitch level at the beginning of the unit; (3) pause: a pause at the beginning of the unit (in effect, between two units; (4) anacrusis: a sequence of accelerated syllables at the beginning of the unit; (5) lengthening: a prosodic lengthening of syllable(s) at the end of the unit (e.g., of the last syllable in the unit)" (100).

\section{Methodology: Participants, Corpus and Experimental Design}

The subjects for the experiment were four university students at the Autónoma Univeristy of Madrid. Although the number of subjects may be considered insufficient, the specific characteristics of the present experiment allow the number to be adequate. As Ramírez Verdugo reports (2003: 43), relevant literature on learner corpus (Sinclair 1995, Milton 1996, Meyer 2002) reveals that - apart from the specificities of each experiment - a corpus size will mainly depend on the difficulties of taking into account all the sociolinguistic and the purely linguistic variables. All the subjects were female in order to avoid the pitch range variable in male and female speakers. The male fundamental frequency (F0) ranges between $60 \mathrm{~Hz}$ and $240 \mathrm{~Hz}$; female pitch range is between $180 \mathrm{~Hz}$ and $400 \mathrm{~Hz}$. The average fundamental frequency for men is approximately $120 \mathrm{~Hz}$, for women $225 \mathrm{~Hz}$, and for children $265 \mathrm{~Hz}$ (Cruttenden 1997: 3). From the ones that initially enrolled in our course-experiment, we had to select the Spanish learners whose mother tongue was Castilian Spanish from the Madrid area, the learning of English as a foreign language for more than ten years and the fact that they had never stayed in an English-speaking country. What is more, we chose the subjects who had a minimum requirement of intermediate or B1 from the Common European Framework of Reference and the ones who were also studying beginner courses in languages such as Chinese, Japanese and Arabic. Lastly, from the original ten recorded speakers, four were selected for further analysis, as they produced all the requirements transcriptions, recordings and questionnaires - for making the prosodic course-experiment possible. L2 non-specialist oral presentation or public speaking is the framework of our L2 discourse intonation training and, by the same token, our sub-corpus. To be more precise, the experiment has got both oral and written corpora and therefore quantitative and qualitative data. The pre- and post- training tasks were used to quantify a possible prosodic development of a nine-week L2 discourse intonation training. Our course comprised eighteen input sessions, 160 minutes each week (1,440 minutes total hours), and all sessions took place in the classroom. Praat (free software for speech analysis. Version 5.1.07) was employed to obtain the acoustic data. The subjects' oral presentations were recorded with a digital PCM (Pulse Code Modulation) voice recorder and two built-in round dynamic speakers, 8 ohms, $200 \mathrm{~mW}$ output. All files were saved in WAV format for acoustic analysis. 
The pre- task included a given topic for all subjects ("Advantages and Disadvantages of Living and Studying in Spain") in which they were asked to give an oral presentation following a set structure (Craven 2008). After the presentation, subjects were asked to complete a questionnaire regarding discourse organisation and speaking style. None of the pre- tasks involved any implicit or explicit L2 prosodic training. The training sessions were mostly taken from Brazil's Pronunciation for Advanced Learners of English and the most relevant units for the development of L2 discourse intonation in monologic discourse were selected. The L2 discourse intonation training course of the present experiment lasted for nine weeks and comprised eighteen sessions with a total classroom time of 1,440 hours. The course programme was evenly arranged in three blocks of six sessions each. The first six sessions provided a general introduction of the English intonation system, annotation of the basic forms in English intonation (tone units, prominence, tonic syllable and tone) and an introduction of Brazil's well-known discourse function of proclaiming and referring. The central part of the course (sessions seven to twelve) presented and developed the parameters associated with the pragmatic function of dominance and control, i.e. tone, key, termination, unfilled pause and filled pause. The last block (sessions thirteen to eighteen) was aimed at revising and consolidating the areas that were explored during the first and second blocks of the training course.

\section{Analysis and Discussion}

\subsection{Tone Choices in L2 Discourse Intonation to Express Dominance and Control}

This section aims to analyse and compare how prosodically competent our subjects can be before and after an L2 discourse intonation training course in relation to their production of tones. First, attention will be drawn to a quantitative comparison of the 0 or level tone, a prosodic parameter that can become an agent of oblique discourse, and non-level tones that are the prosodic resources for creating a more communicative discourse. After that, the correspondence between the form and function of non-level tones will be analysed in order to consider whether an oral presentation is dominant or nondominant.

The following table shows a general reduction of proclaiming (falling) tones and, more importantly, the number of level (or 0) tones after the intonation-training programme. Three out of four subjects managed to keep the level tone to expected occurrences. Regarding the two tones associated with dominance and non-dominance, only one subject chose to use more dominant rising $(\mathrm{r}+)$ after an awareness-raising training of its pragmatic implications. Non-dominant fall-rise (r), however, was more systematically employed by all the subjects in their final presentations. The other dominant tone (risefall or $\mathrm{p}^{+}$) also increased in number by all the speakers at the end of our L2 discourse intonation course. The following paragraphs are a more detailed analysis of the form-function interface between dominance and non-dominance within the context of L2 monologic discourse. 
FS $1=$ Female Subject 1; FS2 $=$ Female Subject 2; FS3 = Female Subject 3; FS4 $=$ Female Subject 4; BIT = Before Intonation Training; AIT = After Intonation Training

\begin{tabular}{|c|c|c|c|c|c|c|c|c|c|c|c|c|}
\hline \multirow[t]{2}{*}{ SUBJECT } & \multicolumn{2}{|c|}{$\begin{array}{l}\text { TOTAL } \\
\text { TONES }\end{array}$} & \multicolumn{2}{|c|}{$\begin{array}{c}\text { FALL } \\
\text { (p) }\end{array}$} & \multicolumn{2}{|c|}{$\begin{array}{c}\text { RISE } \\
(\mathrm{r}+)\end{array}$} & \multicolumn{2}{|c|}{$\begin{array}{l}\text { FALL- } \\
\text { RISE } \\
\text { (r) }\end{array}$} & \multicolumn{2}{|c|}{$\begin{array}{c}\text { RISE-FALL } \\
\left(p^{+}\right)\end{array}$} & \multicolumn{2}{|c|}{$\begin{array}{l}\text { LEVEL } \\
\text { (0) }\end{array}$} \\
\hline & BIT & AIT & BIT & AIT & BIT & AIT & BIT & AIT & BIT & AIT & BIT & AIT \\
\hline FS1 & 130 & 122 & 81 & 77 & 21 & 14 & 9 & 14 & 4 & 14 & 15 & 3 \\
\hline FS2 & 187 & 137 & 72 & 61 & 43 & 54 & 7 & 12 & 1 & 3 & 64 & 7 \\
\hline FS3 & 342 & 267 & 123 & 118 & 92 & 66 & 16 & 30 & 0 & 35 & 111 & 18 \\
\hline FS4 & 279 & 298 & 98 & 117 & 92 & 65 & 2 & 8 & 10 & 29 & 77 & 79 \\
\hline
\end{tabular}

FS1's 15 level tones before intonation training account for $11.54 \%$ of total tones in her first presentation. This could be considered a reasonably acceptable percentage for L2 public speaking since, as Brazil noted (1994: 23), "we must expect involuntary uses of level tone". What seems noticeable is the reduced number of level tones after intonation training (3). This can be interpreted in the light of possible effects of our intonation training programme before FS1's final discourse. When FS1 responded to a question about the dominant or non-dominant status of her AIT speech, her response was that she "tried to do it in a dominant way. I think it looks better on a presentation". This statement does not seem to correspond to our quantitative data since the number of dominant rising $(\mathrm{r}+)$ after intonation training decreased (21 BIT - 14 AIT) and the non-dominant falling-rising ( $r)$ increased (4 BIT - 14 AIT). These results seem to show discrepancy between the form of tones and the L2 speaker's discourse-pragmatic dominance and control. Lastly, the rise-fall tone $(\mathrm{p}+)$, the other tone to express dominance, also deserves some close inspection and analysis. Brazil's seminal work (The Communicative Value of Intonation in English) assigns the dominant implication to the rise-fall, although he recognises that it is based on relatively few data samples. This fact leads him to assign the dominant value to the rising tone and the non-dominant to the fall-rise. He, however, still highlights that the speaker, by choosing the rise-fall, controls his/her discourse when "he/she registers his/her own observations [...] and simultaneously indicates that he/she expects no feedback (1997: 97)". It is important to add that Pronunciation for Advanced Learners (the classroom application of his L2 discourse theory and by extension the basis for our discourse intonation training) does not include the rise-fall and therefore takes a more pedagogical stance by reducing the dominance concept to a dual choice: dominant rise or non-dominant fall-rise. Despite the lack of training on the rise-fall form and function, our data reveals that FS1 doubled the number of rise-fall tones in her final presentation (4 BIT - 14 AIT). From the four rise-fall choices made by FS1 in her initial presentation, only one case expresses her own observation (and expects no answers), in this case her claim that Spain is a sunny country is based on factual information. The other three cases of rise-fall are all discourse frames, language phrases o with no other value than letting the listener know where exactly the speaker is going in his/her discourse. On the other hand, the after-training speech shows seven uses of rise-fall to express FS1's own observations and seven cases of discourse frames.

FS2's excessive amount of level tones in her first presentation can be interpreted in the light of the informant's post-performance questionnaire. BIT questionnaire reveals that FS2 memorised the speech but she "forgot a lot of things and I didn't do the presentation as well as I wanted". FS2 had also to improvise the "forgotten" parts so the combination of excessive reliance on memory and improvisation made the speech monotonous and very irregular in pace. Conversely, the number of level tones was severely reduced in her final presentation since this time FS2 used her transcription with the annotated tone units, prominent syllables and tones. This annotated transcription could have helped her make her speech more message-oriented rather than language-oriented; i.e. a discourse more appealing to the 
listener rather than a mere reproduction of the language. Regarding dominant tones, FS2 seems to have partially aligned the rising tone $(\mathrm{r}+)$ with its discourse-controlling implications. Being asked about the dominant or non-dominant status of her AIT speech, her response was that "my presentation was dominant because I used high pitch a lot". The above chart indicates the $r+$ tone has increased in the final presentation, but FS2 has also made use of more non-dominant fall-rise (r). This conflicting datum would denote an inconsistent application of the prosodic form-function interface. The less-frequent risefall for dominance is also applicable to FS2's pre-and-post speech performance. Our subject chose the $\mathrm{p}+$ tone only two more times than in the first presentation (1 BIT - 3 AIT). As regards the dominant implications of $\mathrm{p}^{+}$, all the choices (both BIT and AIT) reflect the speaker's personal perception of living and studying in Spain.

In her BIT questionnaire, FS3 sets out the reasons for using a rather unbalanced amount of level tones (111). Regarding pre-training speaking style, FS3 commented that "a kind of summary for each of the three parts" was prepared for the body part of the presentation. For the delivery of her aftertraining presentation, FS3 confirmed that "I followed my notes a bit, although I also improvised some parts of the speech". Therefore this partly impromptu speech style seems to have caused an excessive use of level tones which ended up uttering an intonationally flat discourse. The above mentioned awareness-rising activities during the intonation-training course could have had an effect on our informant and made her reduce the number of level tones in her final discourse (18). Another contributing factor could have been the circumstance that in her final speech, "although maybe I got stuck in one or two words," she "didn't improvise because I had my transcript in front of me and it helped a great deal". When it comes to the dominant versus non-dominant choice, FS3 clearly stated in her AIT questionnaire that her "presentation was mostly non-dominant". Our data confirm that FS3 almost doubled the number of non-dominant fall-rise (16 BIT - 30 AIT) while the dominant rise was severely reduced (92 BIT - 66 AIT). Another close inspection to our FS3's final questionnaire could shed some light on an initially misleading data - the number of dominant rise-fall (0 BIT - 35 AIT). Her choice for dominant rise-fall may have been mainly accidental since she listened to her first presentation and notice her "habit of sounding always in low pitch and forgetting about differentiating between falling and rising". Since FS3 did not choose any rise-fall in her first public speech, this last statement may be viewed as her attempt to produce a wider range of tone choices but not a conscious choice of the rise-fall form and its pragmatic function. In fact, FS3's rise-fall was not only used to formulate her own opinions but also for a variety of purposes; i.e. referring to different parts of the discourse, clarification of terms, phrases for gaining time to think and in all the elements of a close list.

FS4 was the only subject who was not able to reduce the number of level tones. Our qualitative data - initial and final questionnaires - have become useful tools in order to interpret our quantitative results. Before-training indicates that FS4 wanted to follow her notes but got nervous. She also "followed some key words and improvised some parts". After-training reveals that, before the final speech, she tried to memorise the discourse structure and some key words to follow the structure. As in her first presentation, FS4 also improvised some parts although did not remember where exactly. The other analysed subjects comparatively did improvise some parts of their initial speech but, on the other hand, they followed their transcripts with prosodic annotation for the final speech. As FS4 did not follow her prosodic transcript, this could have been a decisive factor for not reducing the number of level tones in her final presentation. When it comes to choosing between a dominant and a non-dominant stance, FS4 did not seem aware of the option she was supposed to choose. Quantitative data registers an increase of the non-dominant fall-rise (2 BIT -8 AIT) and decrease of the dominant rise (92 BIT - 65 AIT). Qualitative data, on the other hand, reinforces FS4's ambiguous attitude as she thought her last presentation "was non-dominant but there were both parts [dominant and non-dominant]". Interestingly, there were more dominant rise-fall the in the final presentation (10 BIT - 29 AIT). All the cases of risefall in the first presentation were used to formulate her own opinions, except for two cases where two level tones preceded the rise fall. This level and then rise-fall could be interpreted as a way to regain pitch movement in discourse. The rise-fall in her final speech, however, did not match its form to its 
main pragmatic function. Although there were cases where the rise-fall was used to formulate FS4's own opinions, $\mathrm{p}^{+}$was also employed to clarify previous information, discourse frames and proclaiming (new) information.

\subsection{Length of Key and Unfilled Pause in L2 Discourse Intonation (Public Speaking) to Express Dominance and Control}

Having delved into a L2 prosodic comparison of tone choices, a public speaker can also choose other prosodic parameters such as key and unfilled pause to exert dominance and control. In fact, high key plays a crucial role in this study since this speaker's choice can be made to indicate something new or different in the discourse argument. By the same token, the stages in public speaking coincide with the points where unfilled pauses can be used consciously by a public speaker. By making deliberate pauses, the public speaker draws attention to the newly introduced topic. The framework we are using in the table from this section (De Vito 2012: 202) is a tool to measure and contrast not only the length of pauses but also the use of key in order to create phonological paragraphs. The table will be followed by an individual analysis of our informants in relation to possible patterns or asymmetries the way they selected high keys and/or unfilled pauses.

Table two reveals that most subjects chose a higher key in the first tone unit to cue the beginning of a new topic in their after-training L2 public speaking. FS1 $(+37.7 \mathrm{~Hz})$, FS2 $(+45.3 \mathrm{~Hz})$ and FS3 $(+80.8$ $\mathrm{Hz}$ ) increased the mean high key at the strategic new-topic landmarks of their L2 public speeches. FS4 $(-02.5 \mathrm{~Hz})$ was the only subject whose AIT mean F0 maxima decreased. As regards length of unfilled pauses, FS1 $(+34 \mathrm{sec}), \mathrm{FS} 3(+0.13 \mathrm{sec})$ and FS4 $(0.31 \mathrm{sec})$ were able to make longer mean pauses as a means to mark the beginning of a new point in their AIT presentations. Only FS2 $(-0.17 \mathrm{sec})$ made her mean AIT length of pause shorter. Lastly, FS2, FS3 and FS4 were able to use simultaneously high key and pause at the beginning in at least half of the DeVito's designated new topics in public speaking. Conversely, FS1 achieved a dominant high key plus unfilled pause in only one new topic. As for the other new topics, higher key was interchanged for shorter pause and vice versa.

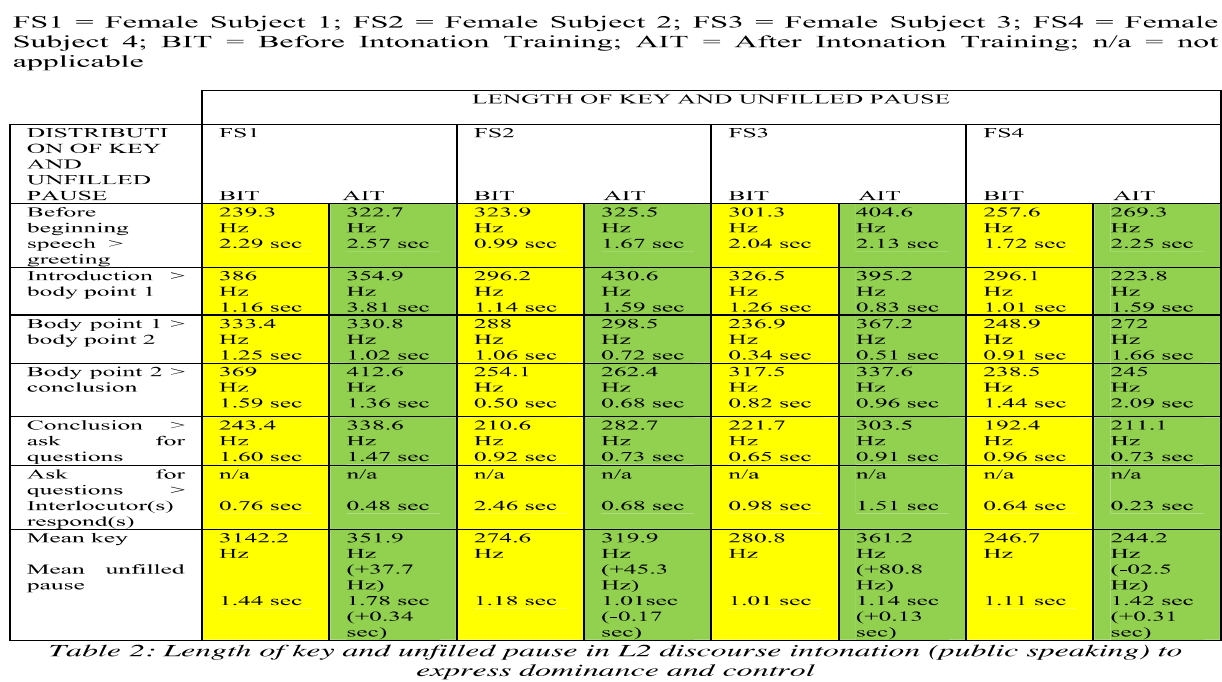

Training on identifying and producing high key to signal a new discourse topic may have had an effect on our subjects since FS1 achieved a higher mean key in her final presentation (314.2 Hz BIT $351.9 \mathrm{~Hz} \mathrm{AIT/}+37.7 \mathrm{~Hz}$ ). A closer inspection indicates, however, that our subject has not been able to 
provide the topic-introducing tone unit with the highest F0 maximum consistently throughout her whole AIT speech. Introduction and conclusion were signalled with higher keys after the intonation training, but the main points in the body part alternated symmetrically between lower and higher keys before and after intonation training. This general lack of consistency could indicate a possible need to have more training sessions on the form and function of key since our intonation training is based on Brazil's Pronunciation for Advanced Learners and this work was originally designed with more sessions on tones rather than keys. Regarding the use of unfilled pauses, FS1 was also able to obtain longer unfilled pauses in her final presentation $(1.44 \mathrm{sec}$ BIT $-1.78 \mathrm{sec}$ AIT/+0.34 sec). Although post-training speech indicates a general increase in the length of pauses, a lack of consistency in the conscious use of pauses at the beginning of each main phonological paragraph can also be detected. FS1's introductory and first body point pauses were made longer while pauses in the body point 2 and conclusion were made shorter. This could indicate a need to have more training on deliberate and conscious use of pauses. Lastly, a correlation between unfilled pause and key needs a closer inspection. At the beginning of two pause landmarks FS1 used shorter pauses but higher keys - body point $2>$ conclusion and conclusion $>$ ask for questions. The other noticeable pattern is either longer pause and higher key - before beginning speech $>$ greeting - or shorter pause and lower key - body point $1>$ body point 2 . The longer pause but lower key option was chosen once (introduction>body point 1 ). This could be interpreted as a deviation from an ideal dominant speaker who integrates and deliberately use longer pauses with higher keys. This last point leads us to think that our subjects, as noted earlier, may have needed more work on both variables during their training course.

FS2's data also shows a general increase in key $(274.6 \mathrm{~Hz}$ BIT $-319.9 \mathrm{~Hz} \mathrm{AIT} /+45.3 \mathrm{~Hz})$. What is more, F2 seems to have been more consistent in her use of key - compared to FS1 - in order to cue a new discourse topic. FS2 chose to make higher keys at the beginning of three designated new topics of her final speech. For her post-training speech, as she stated in her final questionnaire, FS2 did not memorise some parts of her speech and did not improvise, but mainly read from her script with the annotated prosodic symbols; including the upward arrow for key and triple slant brackets (///) for long pause that we learnt during the course. She also seemed aware of the importance of high pitch (key) as she "used high pitch a lot". When it comes to comparing the length of pauses, FS2 - unlike FS1 - made her pre-topic pauses shorter in her after-training presentation (1.18 sec BIT - $1.01 \mathrm{sec}$ AIT/-0.17 sec). The pauses before beginning of speech, body point 1 and body point 2 were longer while the other initial-topic pauses were shorter. All in all, FS1 and FS2 seem to share irregular patterns in their use of pauses but FS2 has shown to be more in control in her general use of high key and pause. Even though FS2's average pitch range was lower than FS1, FS2 was able to make higher key in all the topics after the intonation training while FS1 fluctuated between higher and lower key in the body paragraphs. This last point could be an indication of the benefits of an L2 intonation course to improve prosodic performance in public speaking. Despite initial pre-training differences at language level (FS1 had a C1 level. FS2's level was B1), FS2's comparative analysis has verified that a training on the form and use of key subsequently can have a positive effect on the speaker's prosodic performance.

FS3 scored the highest increase in initial-paragraph key in the after-training speech $(280.8 \mathrm{~Hz} \mathrm{BIT}$ - $361.2 \mathrm{~Hz} /+80.8 \mathrm{~Hz}$ ). Our subject, like FS2, signalled four initial-topic landmarks higher in key at three crucial stages in her final presentation; before beginning speech $>$ greeting, body point $1>$ body point 2 , body point $2>$ conclusion and conclusion $>$ ask for questions. There was only one stage (introduction>body point 1) in which initial-paragraph higher key and shorter pause were made. Concerning unfilled pauses, FS3 was also able to increase the length of unfilled pauses in her final presentation (1.01 sec BIT $-1.14 \mathrm{sec}$ AIT/ $+0.13 \mathrm{sec})$. What is more, FS3 seems to have been able to make deliberate and effective pauses just before the new discourse parts, although she was the third subject with the best mean of unfilled pause after intonation training. However, this latter datum should not be deemed to have a special relevance due to the fact that FS3 was more consistent in her simultaneous use of key and pause to mark the beginning of a new topic. Her control in using these two prosodic parameters could have been possible partly thanks to her pre-training language level (C2 in 
grammar and use of English) and her active involvement in our L2 discourse intonation training course as she volunteered to be recorded for the final task at the end of each session and asked for a one-toone tutorial before the final presentation.

FS4 has been the only subject who could not improve the mean high key in her final presentation (246.7 Hz BIT - 244.2 Hz AIT/-02.5 Hz). On the other hand, table 2 shows that on three occasions FS3 made higher keys and longer pauses. FS4's mean was $+83.9 \mathrm{~Hz}$ in four cases, FS2's mean was +48.1 $\mathrm{Hz}$ in three cases, FS1's mean was $+83.4 \mathrm{~Hz}$ in one case, and FS4's mean was $+13.8 \mathrm{~Hz}$ in three cases. The other two designated speech paragraphs had different patterns: introduction>body point 1 had lower key but longer pause and conclusion>ask for questions had higher key but shorter pause. As for the length of unfilled pauses, FS4 attained better results in her AIT presentation (1.11 sec BIT - $1.42 \mathrm{sec}$ $\mathrm{AIT} /+0.31 \mathrm{sec})$. In fact, FS4 obtained the second best mean of unfilled pauses and in only one case (conclusion>ask for questions) the AIT length of pause was shorter than before the intonation training. Lastly, FS4 was not able to make a simultaneous use of key and unfilled pause in the after-training discourse and therefore this could have reflected dominance in signalling new discourse topic.

\subsection{Number of Filled Pauses and Other Hesitation Phenomena in L2 Discourse Intonation (Public Speaking) to Express Dominance and Control}

A deliberate increase in unfilled pause can enhance the control over the L2 speaker's discourse. Conversely, a reasonable decrease of filled pauses can have the same effect in monolingual discourse. In fact, Brazil (1997) holds the view that hesitation phenomena and level tones do not contribute to express discourse dominance and control: "pause-fillers, themselves non-selective items (since they have no word status within the language system) frequently serve as dummy carries of the [level] tone (1997: 139)". Therefore this stance leads logically to propound that dominant (strategic) avoidance of filled pauses can be a reliable quantitative parameter in effective public speaking which requires a close analysis. This section starts with a record (table) of the most significant types unfilled pause or hesitation phenomena (Hieke 1985) before and after the L2 discourse intonation training course and it finishes with an interpretation of the table by means of an individual comparison of each subject's quantitative and qualitative data.

Table three displays a general reduction in the number of filled pause (hesitation phenomena) after our intonation training programme. In fact, all our informants improved their results in the control over the different hesitation areas. The only exception was FS1 who made double progressive repeats in her post-training discourse ( 3 BIT -6 AIT). It was precisely FS1 who made the fewest hesitation phenomena before and after discourse training course. The other informants made more hesitation phenomena but they also achieved more reductions. Filled pause has the most cases before intonation training, followed by phonetic lengthening and progressive repeats, respectively. The lowest cases before and after intonation training are in the area of false starts. 
Analysing Four Prosodic Forms to Convey the Pragmatic Function of Dominance ... Jimenez Vilches

FS1 $=$ Female Subject 1; FS2 $=$ Female Subject 2; FS3 $=$ Female Subject 3; FS4 $=$ Female Subject 4 ; BIT $=$ Before Intonation Training; AIT $=$ After Intonation Training

\begin{tabular}{|c|c|c|c|c|c|c|c|c|c|c|}
\hline \multirow{3}{*}{ SUBJECT } & & & \multicolumn{8}{|c|}{ HESITATION PHENOMENA } \\
\hline & \multicolumn{2}{|c|}{$\begin{array}{l}\text { TOTAL } \\
\text { HESITATION } \\
\text { PHENOMENA }\end{array}$} & \multicolumn{2}{|c|}{$\begin{array}{l}\text { STALLS: } \\
\text { FILLED } \\
\text { PAUSES }\end{array}$} & \multicolumn{2}{|c|}{$\begin{array}{l}\text { STALLS: } \\
\text { PROGRESSIV } \\
\text { E REPEATS }\end{array}$} & \multicolumn{2}{|c|}{$\begin{array}{l}\text { STALLS: } \\
\text { DRAWLS }\end{array}$} & \multicolumn{2}{|c|}{$\begin{array}{l}\text { REPAIRS: } \\
\text { FALSE } \\
\text { STARTS }\end{array}$} \\
\hline & BIT & AIT & $\mathrm{BI}$ & AIT & $\mathrm{BI}$ & AIT & BIT & AIT & BI & AIT \\
\hline FS1 & 13 & 11 & 2 & 1 & 3 & 6 & 5 & 1 & 3 & 3 \\
\hline FS2 & 54 & 14 & 17 & 3 & 12 & 6 & 23 & 4 & 2 & 1 \\
\hline FS3 & 106 & 9 & 44 & 0 & 16 & 1 & 39 & 8 & 7 & 0 \\
\hline FS4 & 115 & 90 & 42 & 41 & 28 & 21 & 39 & 27 & 6 & 1 \\
\hline
\end{tabular}

Table 3: Number of filled pauses and other hesitation phenomena in L2 discourse intonation

(public speaking) to express dominance and control

FS1's progressive repeats after intonation training were double than before intonation program (3 BIT - 6 AIT). This could be interpreted as a consequence of FS1's speaking style; she spoke from her transcript so she may have wanted to remain faithful to the text and, almost unconsciously, make herself repeat certain passages of the speech. Regarding self-correction, FS1's repairs are the same before and after intonation training. From the three false starts before intonation training, two were content word related - verb and noun - and one was a function-related word such as articles. FS1's speech after intonation training revealed two content word repairs (verbs) and one function word repair (preposition). More content self-correction could be an indication of FS1's interest for content-related accuracy since the main ideas in her body paragraphs were related to actions Spanish students can take in Spain or abroad. Differences in hesitation phenomena (filled pauses and drawls) have also been analysed. Filled pauses were reduced in the speech after intonation training. Two cases of "ahhh" in the initial speech were counted while there was only one case ("uuum") in the final presentation. Regarding drawls, there were three cases of [i:] and one [a:] phonetic lengthening in the initial presentation. Speech after intonation training did not reveal any occurrences of vowel lengthening but only one consonant [th:]. This decrease in phonetic lengthening could have been partially achieved through a positive selfevaluation as she described her own final presentation using the adjectives "fluent" and "variation in voice".

FS2's oral performance after our experiment exhibits an outstanding performance when it comes to avoiding non-fluency devices. Her initial twelve progressive repeats were reduced to six in the final presentation. Unlike FS1, there was one case of bridging repeat in the final speech only - "the repeated element retrogressively tracing the constituent to its beginning to permit both semantic and temporal cohesion" (Hieke 1985: 139). FS2 herself stated that she gained in confidence in her final presentation due to reliance on her intonation transcript; this more sophisticated type of repetition could be perceived as a consequence of her more confident speech after the intonation course. When it comes to selfcorrection, a numerical decrease in FS2's final speech was also annotated. From the two false starts in the initial speech, one was grammatical (modality) and the other was content based. After-performance presentation reveals one case of self-correction only - phonemic slip in "firty" and after a brief pause the corrected "thirty five". Lastly, the two hesitation phenomena - filled pauses and phonetic lengthening - diminished considerably in her final speech. Twelve "eeeh" filled pauses were counted in her initial presentation and the remaining three were the variation "eeemm", "aie" and the Spanish filler "bueno". From the initial fifteen unfilled pauses, FS2's final speech was reduced to a mere three "eeeeh" hesitations. Drawls (phonetic lengthening) in her initial presentation were unconsciously uttered since, being asked about whether she noted any hesitation phenomena in her speech, she did not think she did. Nonetheless, analysis indicates an overuse of phonetic lengthening (23) - mainly front [i:] and back [a:] and [o:]. As Table 2 reveals, a reduction to four cases of phonetic lengthening - two front [i:] and two back [u:] - was achieved in the after-training oral presentation. The exceptional number of filled pauses and phonetic lengthening before intonation training could be viewed as a result of FS2's attempt to memorise her speech. Therefore both phenomena could have been employed to gain time so she could remember the next part of the script. Her final speech, as the post-performance 
questionnaire indicates, was delivered through her intonation transcript, a fact which can explain the strong decrease in the aforementioned quantitative parameters.

FS3 achieved the most remarkable results as the subject was close to eliminate any hesitation traces in her after-training discourse. In fact, our informant did not utter neither filled pauses nor false starts in her post-training speech. After her initial presentation, FS3 was aware of her hesitations since she was asked whether she had noticed any hesitations in her speech and she replied she was aware of "some like 'eeeh', for example". Analysis reveals not only occasional "eeeh" but also other fillers such as "eaaah", "eam", “emmm", "umm", "ammm" and "mmm". Apart from self-awareness, another ameliorating factor could have been a change in the speaking style. As FS3 explained in her initialpresentation questionnaire, she tried to memorise part of her speech. On the other hand, her finalpresentation questionnaire states that she did not memorise it and "rehearsed half an hour each day during the previous week". The other hesitation feature - drawl - also shows an outstanding quantitative reduction. As for vowel lengthening, front [i:] and [e:] and back [a:] and [o:] were mostly employed in the initial presentation. In the same presentation consonants [n:], [s:], [f:] and [l:] were also uttered. Interestingly, final-presentation analysis showed two different vowel drawls - back [u:] and front diphthong [ai:] - while the remaining ones were also utilised in the initial presentation - [i:] and [a:]. However, the only three cases of consonant lengthening in FS3's final presentation - one [n:] and two [s:] - are some of the ones that had already been used in the initial presentation. Lastly, the only one case of progressive repeat in FS3' final discourse may have a direct connection with the aforementioned fact that FS3 decided to move from an initial memorised script to a recall of main ideas and regular rehearsal prior to the final speech.

FS4's self-correction occurrences, like FS3, were notably reduced in the after-training speech. All the self-correction cases before intonation training were language-related; i.e. subject-verb agreement in present simple, changing personal pronouns and correcting a preposition. The only case found in the after-training speech was precisely the correction of the appropriate preposition. The reduction in the number of hesitation phenomena - filled pauses and phonetic lengthening - cannot be deemed to be noteworthy. Only one less filled pause was recounted in post-training speech and the same "eeehs", "umms" and "ammms" were used in both presentations. This fact could have been the consequence of improvising some parts of her speech. FS4 stated in her final presentation questionnaire that, although she only memorised the structure and key words, in the end "I didn't say exactly the words. I improvised but I don't remember where". By trying to construct the final discourse in real time, our informant seems to have employed the same fillers and thus make both presentations sound very similar in relation to the presence of unfilled pauses. Phonetic lengthening - the other hesitation phenomenon - does not reveal a significant reduction in its number either. FS4 employed similar cases of /i:/, /a:/ and /u:/ lengthening in her initial and final public speeches. Phonetic [m:], [n:], [s:] and [f:] were annotated in both discourses, although only in the second presentation[s:] was more prevalent - [m:], [n:] and [f:] were less frequent. The cases of stalls (progressive repeats) were mainly language-related in the presentations before and after intonation training. FS4's initial presentation repeated mostly prepositions and personal pronouns (combined with phonetic lengthening) in order to finish her utterances. Although repetitions of prepositions and phonetic lengthening were still employed, final oral presentation does reveal fewer cases of pronominal repetitions.

\section{Conclusion}

Qualitative data have become essential tools to interpret quantitative data in the present experiment. The tasks to obtain non-numerical information were originally designed to complement the numerical results but in the end it aided the quantitative data to be interpreted appropriately. For example, the prosodic transcript that the subjects had to annotate for their final presentations have contributed to 
determine whether there was an effective correspondence between the intended prosodic forms and their communicative productions. Other sources such as the after-training questionnaires allowed us to identify whether their tone choices were in line with their intentions to develop prosodically a dominant discourse and not the result of random choice.

Focusing on the observance of purely qualitative data, the findings indicate that there were three main prosodic improvements in the after-training performance of our subjects. Firstly, most subjects were able to control the number of level or 0 tones in their after-training oral presentations. This could have been possible because, during the training course, subjects were warned about the perils of overusing level tones in their oral presentations and were also encouraged to prepare an intonation transcript with annotated tones before their final presentations. As Brazil states (1997: 23), it is somehow normal to find native and non-native speakers hesitating and using level tones in monologic - even more in dialogic - discourses. Teachers and trainers obviously do not need to teach these prosodic features but awareness-raising activities in the classroom can prevent students from overusing level tones. Secondly, subjects were able to produce a wider range of tone choices at the end of our intonation training programme. Most tones in the initial presentation were fall, rise and level. Complex tones such as fall-rise and rise-fall were less frequent. However, all the subjects in their final presentations were able to increase the number of fall-rise and rise-fall. Thirdly, most subjects increased their mean key and unfilled pause in their after-training oral presentations. This happened in at least half of the overall turning points of their L2 discourses. They also achieved to use both concurrent parameters in order to acoustically indicate new topics and, at the same time, show they are speakers who are in control of their own discourses.

On the other hand, our L2 discourse intonation experiment shows a general lack of correspondence between the form and function of tones to express dominance and control. In fact, FS3 was the only subject who was able to double the number or fall-rise in the final oral presentation and confirmed her non-dominant stance through her final-speech questionnaire. The other subjects simply did not match the speaker's choice for discourse-pragmatic dominance or non-dominance with their appropriate form of tones. In fact, these results confirm previous studies since "this lack of "phonological appropriateness' - following Romero-Trillo (2001) - the selection of tones and their subsequent pragmatic implications, may be a common language developmental problem for a considerable number of learners of English [...] (Ramírez Verdugo and Romero-Trillo 2005: 164)". In fact, this inability to match tone choices to specific pragmatic contexts may lead to, if not corrected, "pragmatic fossilization (Romero-Trillo 2002, Ramírez Verdugo 2003)". In order to avoid this pragmatic fossilization, intonation trainers and EFL teachers should provide further practice on the pragmatics-intonation interface as this seems to be a crucial - and often neglected - area in the language development of L2 learners.

Our intention is to develop and improve the specific characteristics of this prosodic training course within the same discourse mode. An after-training reflection made us consider that we could have used Praat (version 5.1.07) as a teaching tool for visual and audio stimuli during the prosodic course. Following Romero-Trillo (2012: 233-234), computer programmes such as Praat and Speech Analyzer can be used as teaching and learning tools aimed at developing students' prosodic performance. This could be implemented in the present study by firstly analyzing the subjects' tones, high / low key, and unfilled pauses on the screen and secondly by comparing them with the selected model samples uploaded by the teachers. This incorporation of analytical techniques into the classroom could be tested in order to measure comparatively results with and without computerized assistance. Another further implication would be to move the present L2 intonation training into an online course of English intonation for Spanish speakers and therefore adapt the tasks and activities of our training course to the speech software and technological tools that this type of virtual education requires. Similar projects (Moyano Fernández, Merino Archivet, Fernández García, Martínez Peinado and Pavón Vázquez 2010; Ramírez Verdugo 2010) have proven to be successful among many Spanish university students from different degrees and backgrounds who have been able to improve their oral speech and transfer it to 
Analysing Four Prosodic Forms to Convey the Pragmatic Function of Dominance ... Jimenez Vilches

their academic and professional settings. This has been possible thanks to the creation and development of an L2 English intonation virtual course which included not only an interactive methodology but also more specifically sound files with prosodically-annotated texts and the screen display of prosodic features through Praat and Speech Analyzer.

\section{Acknowledgments}

The writer would like to thank Dr. Romero-Trillo and Dra. Ramírez Verdugo for their precise advice, insightful comments, and encouragement.

\section{References}

Berkovits, Rochele (1980). Perception of Intonation in Native and Non-native Speakers of English. Language and Speech 23: 271-280.

Boersma, Paul and David Weenik (2010). Praat: Doing Phonetics by Computer [Computer Program]. Version 5.1.07. <http://www.praat.org/> (Accessed November 6 2015).

Bolinger, Dwight (1986). Intonation and its Parts: Melody in Spoken English. Stanford: Stanford University Press.

Brazil, David (1975). Discourse Intonation I. Birmingham: English Language Research Monographs.

Brazil, David (1978). Discourse Intonation II. Birmingham: English Language Research Monographs.

Brazil, David (1985). The Communicative Value of Intonation. Birmingham: English Language Research.

Brazil, David (1994). Pronunciation for Advanced Learners. Cambridge: C.U.P.

Brazil, David (1997). The Communicative Value of Intonation in English. Cambridge: C.U.P.

Brazil, David; Malcolm Coulthard and Catherine Johns (1980). Discourse Intonation and Language Teaching. Harlow: Longman.

Brown, Gillian and George Yule (1987). Discourse Analysis. Cambridge: C.U.P.

Chomsky, Noam and Morris Halle (1968). The Sound Pattern of English. New York: Harper.

Coulthard, Malcolm and David Brazil (1981). The Place of Intonation in the Description of Interaction. In Deborah Tannen, ed., 94-112.

Coulthard, Malcolm and Martin Montgomery, eds. (1981). Studies in Discourse Analysis. London: Longman.

Craven, Miles (2008). Listening and Speaking 3. Cambridge: C.U.P.

Cruttenden, Alan (1997). Intonation ( $2^{\text {nd }}$ edition). Cambridge: C.U.P.

Cruz-Ferreira, Madalena (1987). Non-native Interpretative Strategies for Intonational Meaning. In Allan James and Jonathan Leather, eds., 103-120.

Crystal, David (1986). Prosodic Development. In Paul Fetcher and Michael Garman, eds., 33-48.

Cutler, Anne (1984). Stress and Accent in Language Production and Understanding. In Dafydd Gibbon and Helmut Richter, eds., 77-90.

De Vito, Joseph A. (2012). The Essential Elements of Public Speaking (4th edition). Boston: Pearson Education.

DuBois, John W.; Stephan Schuetze-Coburn; Susanna Cumming and Danae Paolino (1992). Discourse Transcription. Santa Barbara: Santa Barbara Papers in Linguistics.

Gimson, Alferd Charles [revised by Cruttenden, Alan] (2014). Gimson's Pronunciation of English. Oxon: Routledge.

Halliday, Michael Alexander Kirkwood (1963). The Tones of English. Archivum Linguisticum 15: 128.

Halliday, Michael Alexander Kirkwood (1975). Learning How to Mean. London: Edward Arnold. 
Analysing Four Prosodic Forms to Convey the Pragmatic Function of Dominance ... Jimenez Vilches

Hewings, Martin, ed. (1990). Papers in Discourse Intonation. ELR Discourse Analysis Monograph 16. Birmingham: English Language Research, University of Birmingham.

Hieke, Adolf E. (1985). A Componential Approach to Oral Fluency Evaluation. The Modern Language Journal 69.2: 135-141.

Hirst, Daniel and Albert Di Cristo, eds. (1998). Intonation Systems. A Survey of Twenty Languages. Cambridge: Cambridge University Press.

Liberman, Mark and Alan Prince (1977). On Stress and Linguistic Rhythm. Linguistic Enquiry 8: 249336.

Lierberman, Philip (1986). The Acquisition of Intonation by Infants: Physiology and Neural Control. In Catherine M. John-Lewis, ed., 239-257.

Mehler, Jacques; Peter Jusczyk; Ghislane Lambertz; Nilofar Halsted; Josiane Bertoncini and Claudine Amiel-Tison (1988). A Precursor of Language Acquisition in Young Infants. Cognition 29: 143178.

Monroy Casas, Rafael (2001). Profiling the Phonological Processes Shaping the Fossilized IL of Adult Spanish Learners of English as a Foreign Language. Some Theoretical Implications. IJES 1.1: 157217.

Moyano Fernández, Valentín; Ramón Merino Archivet; Nicolás Luis Fernández García; Manuel Martínez Peinado and Víctor Pavón Vázquez (2010). Integración de la Aplicación Informática Fonética 2.0. Sistema de Composición y Generación Dinámica de Animaciones en la Docencia. Córdoba: Consejo Social de la Universidad de Córdoba, 20-23.

O'Connor, Joseph Desmond and Gordon Frederick Arnold (1961). Intonation of Colloquial English. London: Longman.

Pavón Vázquez, Víctor. (2001). La Incidencia de los Procesos de Desarrollo en la Creación de la Fonología de una Segunda Lengua. ELIA 2: 105-115.

Pierrehumbert, Janet B. (1980). The Phonology and Phonetics of English Intonation. Bloomington: Indiana University Linguistics Club.

Pierrehumbert, Janet B. and Julia Hirschberb (1990). The Meaning of Intonation Contours in the Interpretation of Discourse. In Philip R. Cohen, Jerry L. Morgan and Martha E. Polack, eds., 371411.

Prieto Vives, Pilar; Joan Borràs-Comes; V. Crespo-Sendra; Jill C. Thorson and M. M. Vanrell (2011). Entonación y Pragmática en los Enunciados Interrogativos del Español en Habla Dirigida a Niños. ORALIA 14: 227-255.

Ramírez Verdugo, Maria Dolores (2003). A Contrastive Analysis of Non-native Interlanguage English Intonation Systems and their Implication in the Organization of Information from a Functional Perspective. A Study Based on a Computerized Corpus of Spanish Learners of English. PhD diss., Universidad Autónoma de Madrid.

Ramírez Verdugo, María Dolores (2005). Nature and Patterning of Native and Non-native Intonation in the Expression of Certainty and Uncertainty: Pragmatic Effects. The Journal of Pragmatics 37.12: 2086- 2115.

Ramírez Verdugo, Maria Dolores (2006). A study of Intonation Awareness and Learning in Non-native Speakers of English. Language Awareness 15.3: 141-159.

Ramírez Verdugo, María Dolores (2010). Entonación Inglesa a Través de Herramientas de Comunicación en Red: Adquisición de Contenidos, Estrategias y Competencias. Revista Electrónica de ADA 4.3: 232- 239.

Ramírez Verdugo, María Dolores and Jesús Romero-Trillo (2005). The Pragmatic Function of Intonation in L2 Discourse: English Tag Questions Used by Spanish Speakers. Intercultural Pragmatics 2.2: 151-168.

Rogerson, Pamela and Judy B. Gilbert (1996). Speaking Clearly. Pronunciation and Listening Comprehension for Learners of English. Cambridge: Cambridge University Press. 
Analysing Four Prosodic Forms to Convey the Pragmatic Function of Dominance ... Jimenez Vilches

Romero-Trillo, Jesús (2001). A Mathematical Model for the Analysis of Variation in Discourse. Journal of Linguistics 37: 527-550.

Romero-Trillo, Jesús (2002). The Pragmatic Fossilization of Discourse Markers in Non-native Speakers of English. Journal of Pragmatics 34: 769-784.

Romero-Trillo, Jesús, ed. (2012). Pragmatics and Prosody in English Language Teaching. Dordrecht: Springer.

Sinclair, John McHardy and David Brazil (1982). Teacher Talk. Oxford: Oxford University Press.

Snow, David (1995). Formal Regularity of the Falling Tone in Children's Early Meaningful Speech. Journal of Phonetics 23: 387-405.

Snow, David and Heather L. Balog (2002). Do Children Produce the Melody Before the Words? A Review of Developmental Intonation Research. Lingua 112, 1025-1058.

Yule, George (1980). Speakers' Topics and Major Paratones. Lingua 52: 33-47. 